\title{
A FORMAÇÃO CONTINUAdA DOS PROFESSORES ATUANTES NA REDE ESTADUAL DE ENSINO DE MINAS GERAIS
}

A formação continuada só se justifica (...) quando pressupõe uma mudança na prática de ensinar/educar.

Maria de Lourdes Cró

Ana Paula Pereira Arantes ${ }^{1}$, Álex Gomes da Silva ${ }^{1}$, Naime Souza Silva ${ }^{1}$, Tereza de Jesus Ferreira Scheide ${ }^{2}$

${ }^{1}$ Discente do Curso de Mestrado em Educação da UNOESTE. ${ }^{2}$ Docente do Curso de Mestrado em Educação da UNOESTE.

\begin{abstract}
RESUMO
Este artigo tem como objetivo identificar como ocorre a formação continuada dos professores atuantes na rede estadual de ensino de Minas Gerais, mais especificamente das cidades de Iturama e Bonfinópolis. A pesquisa se desenvolveu por meio da abordagem qualitativa, utilizando como procedimento o estudo de caso. Os instrumentos de pesquisa que viabilizaram a consecução do objetivo pretendido foram: aplicação de questionários e entrevistas semiestruturadas. Participaram da pesquisa professores atuantes na rede estadual de ensino de Minas Gerais. Os docentes participantes da pesquisa foram selecionados por cidade, selecionamos as cidades mineiras de Iturama e Bonfinópolis. Participou da pesquisa um docente de cada escola estadual destas cidades que atendiam os seguintes requisitos: possuir mais de um ano de atuação docente na rede estadual e concordar em participar da pesquisa. Com os resultados deste trabalho notamos que há, por parte dos sujeitos da pesquisa, uma esperança de que os programas de formação continuada ministrados pela Secretaria de Estado da Educação tragam "receitas milagrosas" para a melhoria da prática docente. Faz-se necessário conscientizar os professores de que a prática pedagógica só será melhorada a partir do momento em que o professor decodificar o que foi aprendido nos programas de formação continuada e aplicar essa teoria na sua prática de acordo com a sua necessidade e realidade, que pode ser diagnosticada através da sua experiência docente.
\end{abstract}

Palavras-chave: Formação Continuada de professores. Ensino fundamental. Ensino público.

\section{THE CONTINUED FORMATION OF THE TEACHERS OPERATING IN THE PUBLIC EDUCATIONAL SYSTEM OF MINAS GERAIS STATE}

\author{
The continuing education is justified only when (...). \\ Implies a change in practice to teach/educate. \\ Maria de Lourdes Cró
}

\begin{abstract}
The objective of this article is to identify continued formation of the teachers operating in the public educational system of Minas Gerais State, more specifically those who teach in the cities of Iturama and Bonfinópolis. The research was developed in the qualitative boarding, using as procedure the study of case. The research proceedings that made possible the achievement of the intended objective were: the application of questionnaires and half-structuralized interviews. Operating teachers from the public education systems of Minas Gerais State had participated of the research. The teachers who were part of the research were chosen from Iturama and Bonfinópolis, both cities from Minas Gerais State. It was chosen to be part of the research a teacher of each school of both cities that corresponded to the following requirements: has been teaching in public state system for more than one year and has agreed to be part of the research. As results of our work we have notice that there is, on part of those who participated in the research, a belief that the teacher's continued formation programs offered by the State Secretary of Education would bring "miraculous prescriptions" for the improvement of the teaching practice. It's necessary to raise teachers awareness that the pedagogic practice will only be improved from the moment the teacher decodes what has been learned in the continued formation programs and applies the theory in practice according to its necessity and reality, that can be diagnosed through its teaching experience.
\end{abstract}

Keywords: basic education; public education; teacher's continued formation 


\section{INTRODUÇÃO}

As discussões acerca da formação inicial e continuada de professores vêm assumindo destaque nas investigações e publicações da área educacional. Um número considerável e crescente de autores (LIBÂNEO, 2004;NÓVOA, 1995; entre outros) associam a formação continuada ao processo de melhoria das práticas pedagógicas desenvolvidas pelos professores em sua rotina de trabalho e em seu cotidiano escolar.

Nestas discussões parece haver consenso em torno da ideia de que nenhuma formação inicial, seja de nível médio ou superior, é suficiente para o desenvolvimento profissional do professor. Esse consenso põe em destaque a necessidade de se pensar uma formação continuada que valorize tanto a prática realizada pelos professores no cotidiano da escola, quanto - conhecimento que provém das pesquisas realizadas nas instituições de ensino superior, de modo a articular teoria e prática na formação e na construção do conhecimento profissional do professor.

Porém, faz-se necessário que a formação inicial do professor ofereça subsídios para que o mesmo possa desenvolver a sua auto-formação a partir da identificação do campo de trabalho (escola) como lócus de formação docente. Neste sentido Nóvoa (1995, p. 25) destaca que:

A formação deve estimular uma perspectiva críticoreflexiva, que forneça aos professores ao meios de um pensamento autônomo e que facilite as dinâmicas de auto-formação participada. Esta formação não se constrói por acumulação (de cursos, de conhecimento ou de técnicas), mas sim através de um trabalho de reflexividade crítica sobre as práticas de (re) construção permanente de uma identidade pessoal.
Pode-se dizer que a formação continuada é necessária não somente para tentar minimizar as lacunas da formação inicial, mas por ser a escola um espaço (lócus) privilegiado de formação e de socialização entre os professores, onde se atualizam e se desenvolvem saberes e conhecimentos docentes e se realizam trocas de experiências entre pares.

Considerando esta perspectiva, o presente artigo tem como objetivo identificar como ocorre a formação continuada dos professores atuantes na rede estadual de ensino de Minas Gerais, mais especificamente nas cidades de Iturama e Bonfinópolis, a partir da análise da formação destes professores, das formas e frequência de continuidade de sua qualificação profissional e se esta qualificação tem contribuído para a sua prática docente.

\section{PROCEDIMENTOS METODOLÓGICOS}

A pesquisa se desenvolveu por meio da abordagem qualitativa, utilizando como procedimento o estudo de caso.

Para Lüdke e André (1986, p.17) a pesquisa qualitativa "tem $\mathrm{o}$ ambiente natural como fonte de dados e supõe o contato direto e prolongado do pesquisador". Essa característica decorre do fato de que os fenômenos ocorrem naturalmente e são influenciados pelo contexto onde estão inseridos. Sendo assim, compreender as circunstâncias particulares de um determinado objeto é essencial para o desenvolvimento da investigação.

Outra característica importante da pesquisa qualitativa é a de que o significado que as pessoas dão às coisas e à sua vida são focos de atenção especial do pesquisador. Fica claro, que as pesquisas de caráter qualitativo buscam capturar a perspectiva dos participantes e considerar os diferentes pontos de vista dos mesmos. 
A pesquisa qualitativa apresenta-se a partir da obtenção de dados descritivos, coletados diretamente nas situações estudadas, enfatizando as formas de manifestação, os procedimentos e as interações cotidianas do fato investigado, bem como, buscando retratar a perspectiva dos participantes.

Dessa forma, justificamos a escolha pela abordagem qualitativa, uma vez que, são os sujeitos deste estudo - professores atuantes na rede estadual de ensino de Minas Gerais, que forneceram os elementos para esta investigação.

Dentre os procedimentos da pesquisa qualitativa utilizamos o Estudo de Caso. A opção pelo Estudo de Caso decorre do interesse da investigação naquilo que é único e particular do sujeito pesquisado. Lüdke e André (1986, p.17) afirmam que "quando queremos estudar algo singular, que tenha valor em si mesmo, devemos escolher o estudo de caso".

Portanto, compreender a formação continuada dos professores atuantes na rede estadual de ensino de Minas Gerais, a partir da análise da formação inicial destes professores, das formas e freqüência de continuidade de sua qualificação profissional e se esta qualificação tem contribuído para a sua prática docente, configuram-se como os elementos a serem descobertos, descritos, retratados e analisados; caracterizando, dessa forma um estudo de caso.

A pesquisa foi desenvolvida nos municípios mineiros onde residem os pesquisadores autores deste texto: Iturama e Bonfinópolis. Os docentes participantes como sujeitos da pesquisa foram selecionados por municípios e escolas em que atuam. Selecionamos um docente de cada escola estadual existente nos municípios acima citados. Em Iturama existem três escolas e em Bonfinópolis existem duas escolas estaduais, portanto configuraram-se como sujeitos da pesquisa três docentes de Iturama e dois da cidade de Bonfinópolis, totalizando cinco professores, que atenderam os seguintes requisitos: possuir mais de um ano de atuação docente na rede estadual de ensino de Minas Gerais e concordar em participar da pesquisa.

Os participantes da pesquisa serão identificados neste artigo pelos nomes: Bellatrix, Adhara, Sírius, Acrux e Arcturus.

Os instrumentos de coleta de dados da pesquisa que viabilizaram a consecução dos objetivos pretendidos foram:

1. Questionário - foi aplicado objetivando coletar informações que delimite um perfil mais detalhado dos professores, por meio da identificação de dados referentes sexo, idade, titulação e tempo de atuação na rede estadual de ensino de Minas Gerais.

2. Entrevistas semiestruturadas realizadas a partir de um roteiro planejado procurando identificar as formas e freqüência de continuidade de sua qualificação profissional e se esta qualificação tem contribuído para a sua prática docente.

Para nortear a entrevista semiestruturada foi elaborado um roteiro norteador. Também foi utilizado o recurso de áudio-gravação, para posterior transcrição e análise das falas dos sujeitos da pesquisa. Acreditamos que gravando a entrevista temos melhores condições de esclarecer dúvidas, assim como de analisar posteriormente as considerações feitas pelos entrevistados.

Os instrumentos de pesquisa foram aplicados no $1^{0}$ semestre de 2010 , iniciando-se dia 28 de maio e tendo seu término dia 04 de junho de 2010. O questionário foi aplicado aos professores sujeitos desta pesquisa no mesmo dia da realização da entrevista semiestruturada, porém em horário anterior a mesma.

O último passo da pesquisa caracterizouse pela análise dos dados coletados. Essa análise norteou-se de acordo com os seguintes 
critérios: caracterização dos sujeitos da pesquisa a partir da identificação do sexo e idade dos mesmos, formação inicial destes professores, formas e frequência de continuidade de sua qualificação profissional, se e como esta qualificação tem contribuído para a sua prática docente.

Os resultados desta análise estão expressos no próximo tópico.

\section{ANÁLISE E DISCUSSÃO DOS DADOS}

A partir dos dados coletados com a pesquisa de campo identificamos que todos os professores são do sexo feminino e, portanto, vamos referir sobre elas neste artigo como professoras.

De acordo com Bruschini (1988) este fato pode ter como fonte de explicação a própria história da educação, uma vez que no final do século XIX, algumas correntes de pensamento atribuíam às mulheres a socialização das crianças, como parte de suas funções maternas, pois a educação escolar inicial era entendida enquanto uma extensão da formação moral e intelectual que a criança recebia em casa. Portanto acreditava-se que a educação das crianças estivesse mais bem cuidada por uma mulher, a professora.

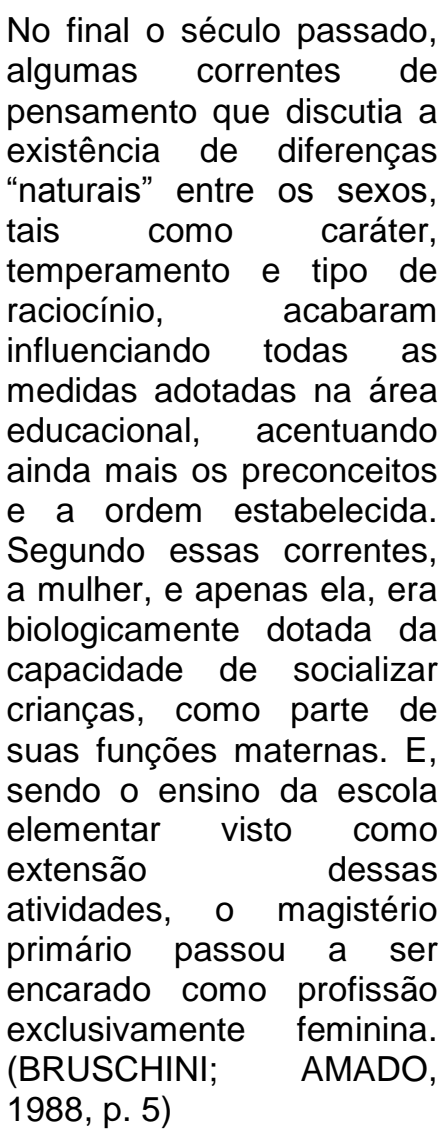

No que se refere à idade das professoras, identificamos que as mesmas têm entre 40 e 47 anos, como pode ser observado na figura abaixo:

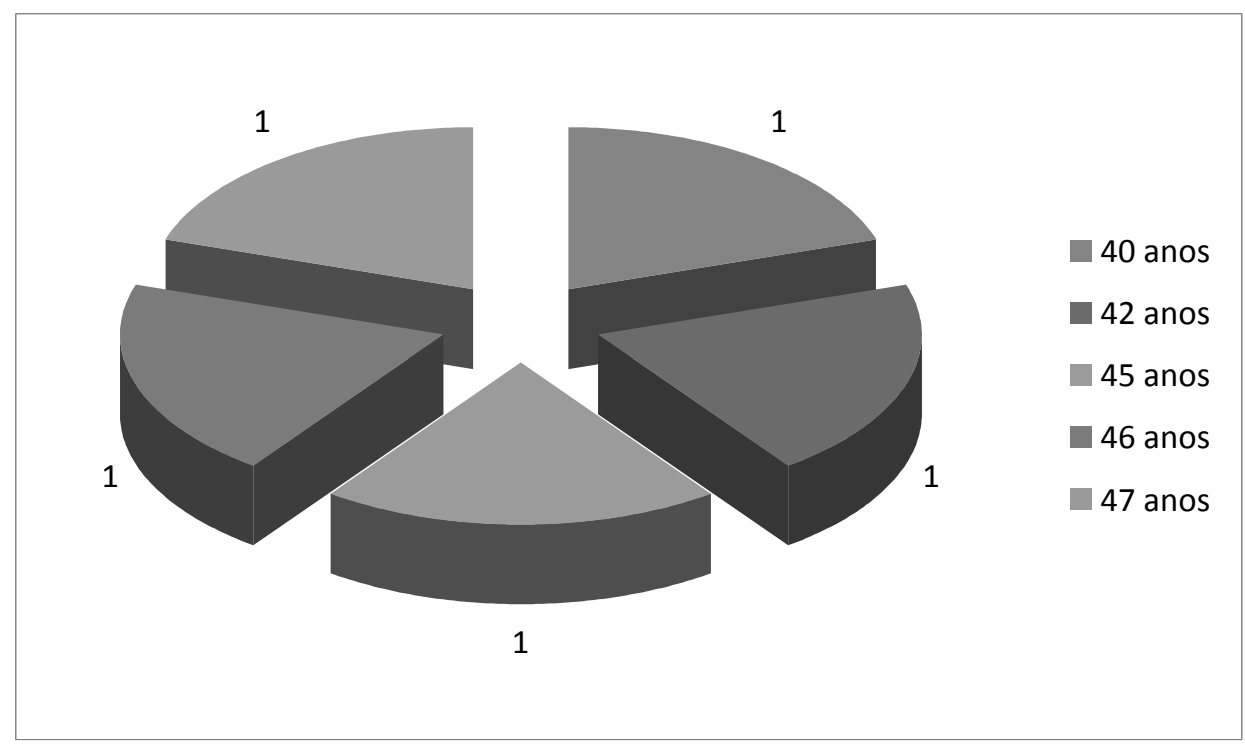

FIGURA 1 - Idade dos professores

Fonte: Pesquisa de Campo 
Sobre a formação em nível de ensino a maioria cursaram a graduação em Instituições de ensino superior privadas.

fundamental das professoras observamos que todas cursaram o ensino fundamental e médio na rede pública de ensino.

Porém ao investigarmos se estas professoras cursaram 0 ensino superior em instituições públicas ou privadas observamos que

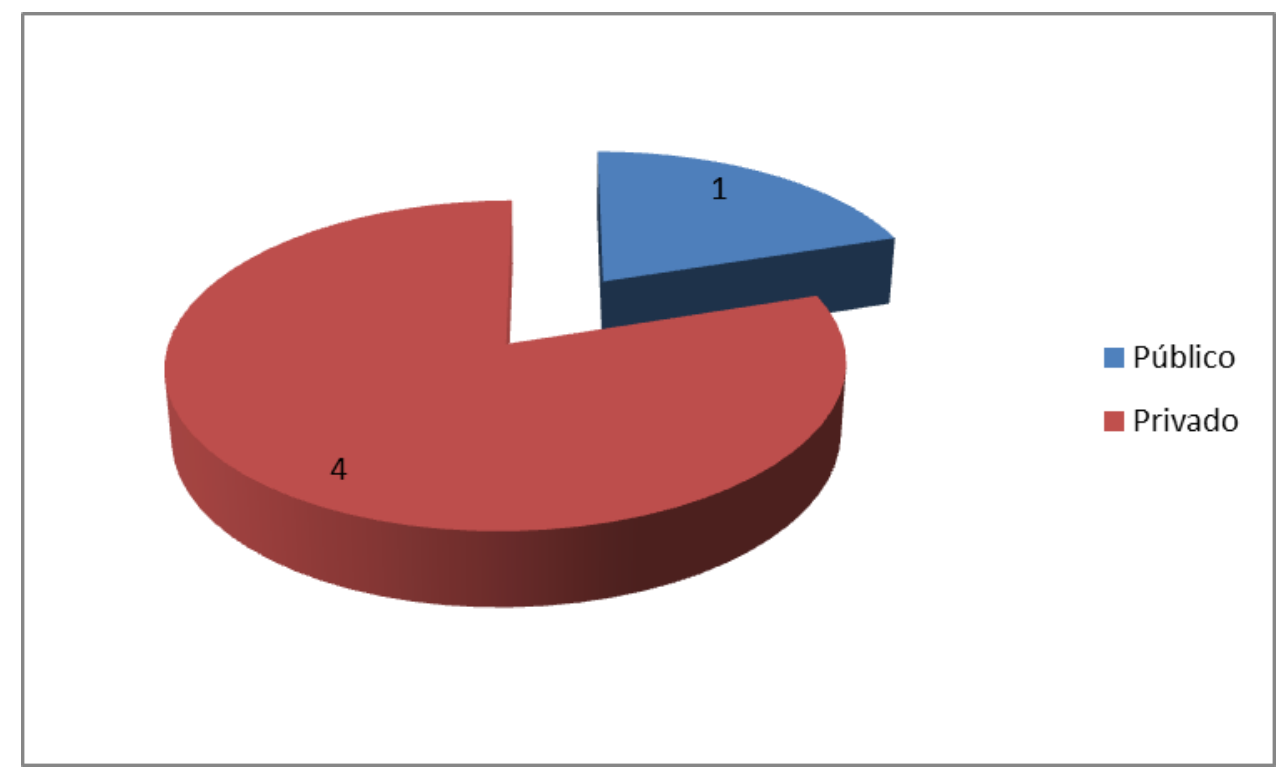

FIGURA 2 - Formação dos professores no ensino superior - Graduação

Fonte: Pesquisa de Campo, 2009

Segundo Sécca e Leal (2009, p.17), este fato pode ser explicado pela expansão do ensino superior privado que aumentou $197,1 \%$ entre 1995 e 2007. Em contrapartida, neste mesmo período o número de instituições públicas aumentou somente 18,6\%. Em 2007, existiam 2.032 instituições privadas e somente 249 públicas. Será que não outros fatores que influenciaram esse crescimento exponencial? Os professores também não sofriam a pressão de ter que concluir 0 ensino superior num prazo determinado pela nova LDB 9394/96. Essa informação é rica e pode ser mais bem explorada no que se refere as análises.

Ao verificarmos se estas professoras cursaram a pós-graduação lato sensu em instituições públicas ou privadas observamos que todas cursaram a pós-graduação em Instituições de ensino superior privadas.

Verificando a formação em nível de graduação destas professoras temos 3 graduadas em Pedagogia, 1 em Letras e 1 graduada em Matemática conforme ilustrado na figura abaixo: 


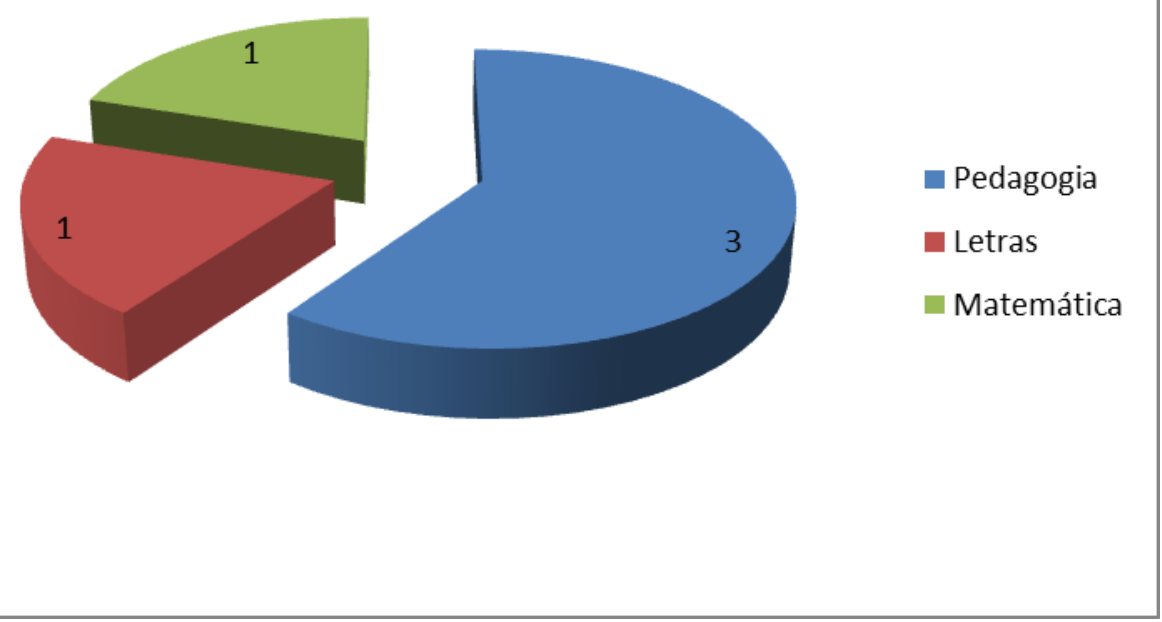

FIGURA 3 - Formação dos professores no ensino superior - Cursos de graduação

Fonte: Pesquisa de Campo

Ao serem questionadas se a formação de graduação as preparou para o pleno exercício da função docente as professoras entendem que a graduação complementa a formação docente, mas não é absoluta nesta preparação. Esta afirmação pode ser observada na fala da professora Adhara:

Em meu curso de graduação e de PósGraduação fui disciplinada e levei muito a sério. Tive excelentes mestres, onde eu me espelho para o meu trabalho. Adquiri um vasto conhecimento dos conteúdos tanto da parte teórica como a de cálculo, e aplicá-los na prática, além de procedimentos didáticos e perfil do professor. As metodologias: Ensino da Matemática e Iniciação à Pesquisa Científica foi um marco essencial na minha formação docente. Enfim, o docente nunca está completamente pronto. $O$ conhecimento é produzido num processo sem fim. A graduação me apresentou as ferramentas, me fez ver os caminhos que um professor consegue realizar um bom trabalho, mas nunca deixa de ser um eterno aprendiz.

Percebemos que a professora está consciente da necessidade de uma formação permanente, que perpassa todas as etapas do trabalho docente.

Parafraseando Imbernón (2009, p. 05) podemos conceituar a formação permanente como o "terreno das capacidades, habilidades e atitudes e que os valores e as concepções de cada professor e professora e da equipe como um todo devem ser questionados permanentemente".

Ainda segundo o autor, esta formação permanente deve ter como base a reflexão dos professores sobre a sua prática docente, de forma que permita examinarem "suas teorias implícitas, seus esquemas de funcionamento, suas atitudes, etc. realizando um processo constante de auto avaliação que oriente o seu trabalho". (p.49)

No que tange ao tempo de atuação destas professoras no ensino fundamental da rede estadual de ensino de Minas Gerais verificamos que este oscila entre 10 a 29 anos, conforme ilustrado na figura abaixo: 


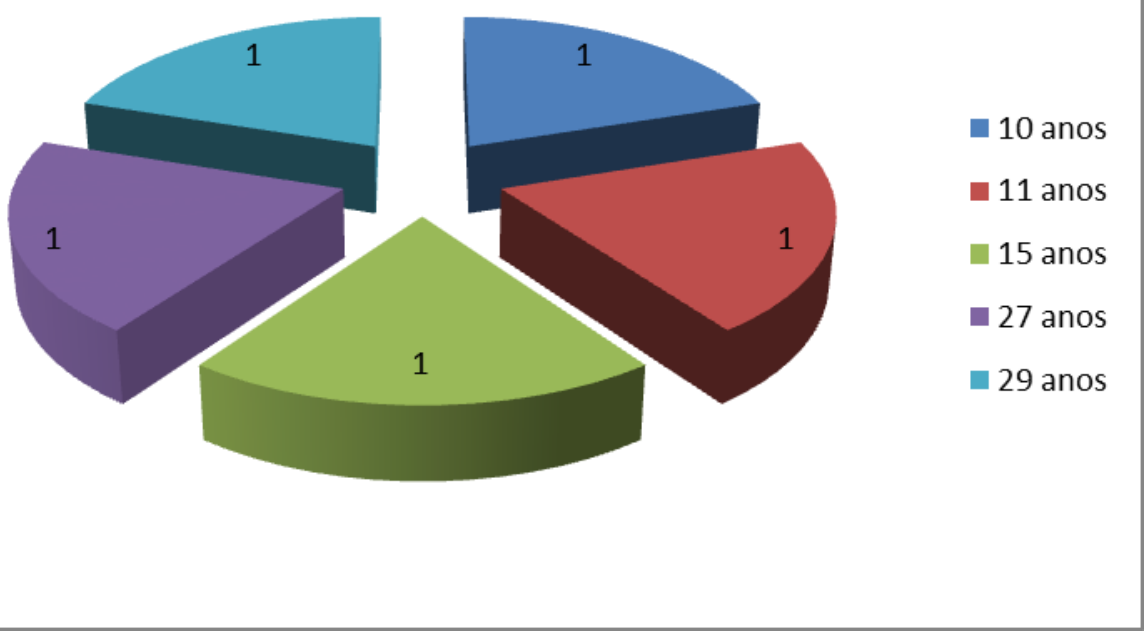

FIGURA 4 - Tempo de atuação como professoras no ensino fundamental da rede estadual de ensino Fonte: Pesquisa de Campo

Considerando o tempo de atuação docente Huberman (2000) apresenta 07 fases referentes ao percurso profissional ou ciclo de vida dos professores: entrada na carreira (1-3 anos), estabilização (4-6 anos), diversificação e questionamento (7-25 anos), serenidade e conservadorismo (25-35 anos) e desinvestimento (35-40 anos).

Percebemos que a maioria dos docentes encontram-se na fase de diversificação e questionamento (7-25 anos). Esta fase, segundo Huberman (2000), caracteriza estes professores enquanto motivados e dinâmicos, buscam a ascensão pessoal administrativa e acadêmica, têm necessidade de contribuir na reformulação do sistema. A fase do questionamento trabalha com componentes psicológicos e sociais envolvendo características da instituição, contexto político e econômico e vida familiar.

Sobre a continuidade da sua qualificação profissional as professoras afirmam continuar esta qualificação por meio de cursos de capacitação e pós-graduação, porém somente uma das professoras (Adhara) citou a experiência profissional enquanto possibilidade de capacitação docente.

Continuo a minha
qualificação profissional
sendo uma estudante,
aprendendo a todos os
momentos: quando
desenvolvo as aulas,
projetos, pesquisas, cursos.
Qualidade é busca, é
inovação, é avanço, é
pesquisa, é estudo.

Neste sentido nos valemos da concepção de Imbernón (2009) considerando que o processo de formação permanente do professor acontece através da reflexão prático-teórica sobre a prática possibilitando ao professor gerar conhecimento pedagógico por meio da sua prática educativa, do conhecimento possibilitado pela troca de experiências entre os seus pares, da união da formação a um projeto de trabalho, da formação como estímulo crítico ante práticas profissionais como o individualismo, a exclusão, a intolerância, etc., assim como do trabalho conjunto possibilitando o desenvolvimento da instituição educativa através da transformação da prática. 
No que ser refere à participação em programas de formação continuada, há diferentes opiniões entre as professoras: A professora Bellatrix afirma que:

Programa de formação continuada inexiste no Estado de Minas Gerais há algum tempo. O último foi em 2002.

Já a professora Arcturus afirma participar destes programas:

Sempre que é oferecido pela Secretaria de Estado de Educação. Acabei de fazer o pro-letramento de Português e Matemática, oferecido pela UFRJ ${ }^{1}$ e pela UFU ${ }^{2}$ com parceria da Secretaria de Estado de Educação".

Um dos motivos a que pode ser atribuído à divergência na opinião destas professoras é o fato de que são de cidades distintas e consequentemente trabalham em escolas estaduais regidas por diferentes Superintendências Regionais de Ensino, havendo assim distinção nos programas de capacitação oferecidos.

Outra observação pertinente é que as professoras Acrux, Adhara e Sírus afirmam participar destes programas sempre que oferecidos pela Secretaria de Estado de Educação.

Neste sentido podemos observar que não existe uma vontade das professoras em procurar outros programas de formação continuada, restringindo a participação em programas oferecidos pela Secretaria de Estado de Educação.

A explicação deste fato pode ter origem em vários fatores, como mais evidentes citamos a carga horária das aulas preenchendo quase a totalidade do tempo de trabalho do professor e o baixo salário que "obriga" o docente a dobrar a sua jornada laboral faltando tempo destinado a outras qualificações que não as cedidas pelo local de trabalho.

Quando questionadas sobre quem promove os programas de formação continuada todas as professoras afirmam que é a Secretaria de Estado de Educação. Portanto não identificamos nenhuma participação da escola na elaboração e promoção destes programas. Isso pode ser observado na fala da professora Arcturus:

A Secretaria de Estado de
Educação prepara os
cursos e manda para as
Superintendências
regionais de ensino que
repassa para as escolas,
manda tudo, apostilas,
professores, as vezes
podemos negociar as datas
mas na maioria das vezes
não. As escolas ficam
apenas como receptoras
destas capacitações, não
tendo nenhuma
participação na elaboração
das mesmas.

As professoras afirmam que estes programas são ministrados nas escolas ou na Superintendência Regional de Ensino e ministrados por:

...pessoas especializadas
nomeadas pela Secretaria
de Estado de Educação.
(Acrux, Sírius, Adhara e
Bellatrix)
...professores da rede
estadual que recebem
capacitação e transferem o
que aprendem. (Arcturus)

Neste sentido concordamos com Mendes (2002, p.1) ao afirmar que uma das críticas mais comumente feitas aos programas de formação continuada incide, muitas vezes, na elaboração de propostas e formação continuada pensadas

\footnotetext{
${ }^{1}$ Universidade Federal do Rio de Janeiro

${ }^{2}$ Universidade Federal de Uberlândia
} 
"de cima para baixo", com a completa exclusão dos docentes.

Ao serem indagadas se estes programas de formação continuada têm contribuído para a prática docente a totalidade das professoras afirmam que sim. Porém, nem sempre a forma desta contribuição é diretamente ligada às necessidades do professor, isso pode ser observado na fala da professora Bellatrix:

Eram cursos excelentes e
contribuíam muito para a
prática docente, uma vez
que sempre superavam
nossas expectativas tanto
pelo conteúdo quanto pela
didática em aplicá-los,
porém nem sempre atingia
a nossa real necessidade.

Sobre os programas de educação continuada, estes são avaliados pelas professoras como bons, porém acreditam que os mesmos deveriam estar vinculados à realidade onde elas (professoras) estão inseridas, como pode ser observado na fala da professora Sírius:

Deveria ter mais prática e
menos teoria. Porque a
maioria destes programas
só trazem teorias
desvinculadas da nossa
prática que não atendem a
nossa real necessidade

Percebemos, portanto, que a formação continuada não deve ser desvinculada das necessidades do docente não compreendendo somente cursos e capacitações, mas sim como um processo de reflexividade docente sobre a prática.

Corroboramos com a concepção de Nóvoa (1995, p.25) no sentido de que a formação continuada "deve estimular uma perspectiva crítico-reflexiva, que forneça aos professores os meios de um pensamento autônomo e que facilite as dinâmicas de auto formação participada". Para o autor esta formação não se constrói por acumulação (de cursos, de conhecimento ou de técnicas), mas sim através de um trabalho de reflexividade crítica sobre as práticas de (re) construção permanente de uma identidade pessoal.

Neste sentido a professora Bellatrix percebe que a formação continuada não deve resumir-se a capacitações isoladas. Ela acredita que:

O nome já diz tudo: formação continuada, então ela deveria acontecer continuamente, quer seja através de cursos na própria escola, com profissionais especialistas, quer seja por centros universitários, ou até mesmo em cursos virtuais, desde que realmente acontecesse na prática $e$ fizesse a diferença na qualidade do ensino, considerando a realidade da escola e a necessidade do professor, que também deve reconhecer e buscar esta necessidade.

Libâneo (2004) vem reforçar esta concepção ao afirmar que:

A formação continuada consiste de ações de formação dentro da jornada de trabalho (ajuda a professores iniciantes, participação no projeto pedagógico da escola, entrevistas e reuniões de orientação pedagógicodidática, grupos de estudo, seminários, reuniões, de trabalho para discutir a prática de colegas, pesquisas, minicursos de atualização, estudos de caso, conselho de classe, etc); Fora da jornada de trabalho (congressos, cursos, encontros, palestras, oficinas); Volta dos professores à universidade para melhoramento do domínio os conteúdos e métodos. È de responsabilidade da Instituição, mas também do próprio professor, que ele 
torne para si a responsabilidade com a própria formação. (p.229)

De acordo com Fusari (1992, p. 25):

A rotina do funcionamento da Escola pode ser a possibilidade de 0 professor aperfeiçoar, continuamente, sua competência docenteeducativa, 0 mesmo podendo ocorrer com diretores, assistentes e demais profissionais que atuam no sistema formal de ensino.

Isso nos leva a considerar a formação continuada não somente como capacitação (cursos, treinamentos, oficinas, etc.), mas como um processo de reflexão sobre a ação, utilizando o espaço escolar como possibilidade de formação docente.

\section{CONSIDERAÇÕES FINAIS}

Pensar em formação de continuada de professores nos remete a pensar a escola como espaço privilegiado de formação continuada. Se nas instituições formais de ensino, o professor realiza sua formação inicial, na escola, local de seu trabalho, ele encontra um espaço que promove sua formação continuada.

Porém identificamos que as professoras participantes da pesquisa restringem a sua formação continuada à participação em programas oferecidos pela Secretaria de Estado de Educação, que nem sempre vêm ao encontro das suas reais necessidades no que tange a prática docente.

Os programas de educação continuada são avaliados pelas professoras como bons, porém acreditam que os mesmos deveriam estar vinculados à realidade onde elas (professoras) estão inseridas.

Percebemos apenas por parte de uma das professoras a concepção da escola (campo de trabalho) enquanto possibilidade de formação continuada, ou seja, processo permanente de aprendizagem pela prática, através da reflexão sobre a própria prática e a troca de experiências.

Faz-se necessário conscientizar os professores de que a prática pedagógica só será melhorada a partir do momento em que o professor decodificar o que foi aprendido nos programas de formação continuada e aplicar essa teoria na sua prática de acordo com a sua necessidade e realidade, que pode ser diagnosticada através da sua experiência docente.

\section{REFERÊNCIAS}

BRUSCHINI, C.; AMADO, T. Estudos sobre mulher e educação: algumas questões sobre 0 magistério. Cadernos de Pesquisa, São Paulo, n. 64 , p. $4-13$, fev. 1988.

FUSARI, J. C. A formação continuada de professores no cotidiano da escola fundamental.. São Paulo: FTD, 1992. p. 25-33. (Série Idéias, n.12).

HUBERMAN, M. O Ciclo de Vida Profissional dos Professores. In: NÓVOA, A. (Org.). Vidas de Professores. Porto: Porto Editora, 2000. p. 3161.

IMBERNÓN, F. Formação docente e profissional: formar-se para a mudança e a incerteza. 7.ed. São Paulo: Cortez, 2009. (Coleção Questões da Nossa Época; v. 77).

LIBÂNEO, J. C. Organização e Gestão da Escola. 5.ed. Goiânia: Alternativa, 2004.

LUDKE, M.; ANDRÉ, M. E. D. A. Pesquisa em educação: Abordagens Qualitativas. São Paulo: EPU, 1986.

MENDES, S. R. A formação continuada de professores e o desafio de romper com os modelos padronizados. Faculdade de Educação da Baixada Fluminense - UERJ. 2002. Disponível em::

<www.anped.org.br/reunioes/25/posteres/soniare ginamendesp08.rtf>. Acesso em: 10 de março de 2010.

NÓVOA, A. (org.). Os professores e sua formação. Lisboa: Dom Quixote, 1995. 
SÉCCA, R. X.; LEAL, R. M. Análise do setor de ensino superior privado no Brasil. Educação BNDES Setorial, n. 30, p. 103 - 156, set. 2009. 